\title{
The Severity of opioid dependence and its relation with psychosocial factors of addicted users.
}

1. MBBS, FCPS (Psychiatry)

Senior Registrar Psychiatry and Behavioral Sciences

Nishtar Medical University, Multan.

2. MBBS, FCPS (Psychiatry)

Assistant Professor Psychiatry and Behavioral Sciences

Nishtar Medical University, Multan.

3. MBBS, FCPS (Neurology)

Assistant Professor Neurology

Nishtar Medical University, Multan

4. MSc, ADCP (Clinical Psychology)

Intern Psychiatry and Behavioral

Sciences

Nishtar Medical University, Multan.

5. MBBS

House Officer Psychiatry and Behavioral Sciences

Nishtar Medical University, Multan.

6. MBBS

Final Year Student

Bakhtawar Amin Medical and Dental College, Multan.

Correspondence Address:

Dr. Owais Kareem

Department of Psychiatry and

Behavioral Sciences

Nishtar Medical University, Multan.

owaiskareem@hotmail.com

Article received on:

08/06/2021

Accepted for publication:

$12 / 08 / 2021$

\section{INTRODUCTION}

Opioid use disorder (OUD) is the problematic illicit use of opioids that causes clinically significant distress or impairment in personal, social and occupational domains of life..$^{1}$ It affects 16 million people worldwide and over 120,000 deaths annually are attributed to opioids. ${ }^{2}$ Opioid use disorder (OUD) includes dependence and addiction with addiction representing the most severe form of disorder. ${ }^{3}$ Opioid dependence includes physical or psychological dependence or both and presents by a reluctance or inability of user to discontinue opioids. ${ }^{4}$

Based on the data presented in United Nations Office on Drugs and Crime, there are 6.7 million (aged 15-64 years) total drug abusers while 0.8 million regular opioid users in Pakistan.
Severity of dependence is high among opioid users moreover substantial regional variation is noted regarding severity of opioid dependence across Pakistan. ${ }^{5}$ Another study reported high prevalence of opioid use among those with adverse psychosocial environment. ${ }^{6}$ Majority of opioid users suffer from severe form of dependence that would require intervention, with nearly 40 per cent of opioid users reporting that they wanted help or treatment for their drug problems. High scores of severity of dependence have been associated with high risk injecting and sexual behaviors that were observed among opioid users. ${ }^{7}$ Effective treatment of opioid dependence incorporates many components, including screening, brief interventions, inpatient, outpatient treatment, evidence based pharmacological treatment and psychosocial interventions, long term residential treatment, rehabilitation, and recovery support 
services. In order to be effective, treatment services must meet the requirements of the individual according to the specific level of severity of their dependence. ${ }^{8}$ Those with mild to moderate opioid dependence, treatment through general health care system may be sufficient, while those with severe opioid dependence may require specialty treatment. ${ }^{9}$

Opioid use disorder are related with multiple psychosocial factors but there is limited data regarding the relationship of severe opioid dependence with psychosocial factors of users. ${ }^{10}$ In this study we intended to highlight those psychosocial areas which are related with severity of opioid dependence so that emphasis would be given to more specific psychosocial interventions appropriate with the severe opioid dependent population.

\section{MATERIAL \& METHODS}

After approval from the ethical review committee this descriptive cross sectional study was conducted from 20-11-2018 to 24-5-2020. Sample size of 196 was calculated by the formula $\left(n=z^{2}\right.$ $\mathrm{p} \mathrm{q} / \mathrm{d}^{2}$ ) by taking 95\% confidence interval, $7 \%$ error of margin, $z$ of 1.96 and $p$ of $50 .{ }^{11}$ Male or female patients of age 18 to 65 years admitted at indoor unit Department of Psychiatry Nishtar Hospital Multan for detoxification treatment of opioid use were included. Patients who had any co morbid addiction of other substances or had any other psychiatric or medical disorders were excluded. Non probability purposive sampling technique was used to collect the sample. Informed consent and confidentiality was ensured for every participant. Data regarding demographics and psychosocial factors was collected on a pre-defined questionnaire. Severity of dependence scale (SDS) was applied to every participant and scores were recorded. ${ }^{12}$ Collected data was analyzed using SPSS 23. Descriptive statistics were reported as frequencies and percentages. Post stratification Pearson chi square test was used to identify the significant relation between severe opioid dependence and various psychosocial factors. Student's t-test was performed to compare the means of groups. $\mathrm{P}$ value equals to or less than 0.05 was considered as significant.

\section{RESULTS}

Total 196 participants were included all were males with the mean age of $30.86 \pm 1.66$ (SD). Severe opioid dependence was noted in 159 $(81.1 \%)$ of study participants. Highest percentage of participants with severe opioid dependence were identified as $<50$ years of age, resided in urban area, were unmarried, lived in joint family system, were literate, matric passed, selfemployed, belonged to middle income class, had opioid use duration of $>12$-month, used sniffing as a preferred route of opioid use, frequency of opioid use was 5 times a day, had previous detoxification treatment, had no family history of drug addictions, had no family conflicts but had encounters with law enforcement agencies (Table-I).

Statistically significant relationship of severe opioid dependence was found with age $(P=0.007)$, literacy status $(P=0.014)$, literacy level $(P=0.07)$, marital status $(P=0.002)$, monthly income $(P=0.00)$, route of opioid use $(P=0.02)$, frequency of opioid use per day $(P=0.01)$, previous detoxification treatment $(P=0.01)$, and encounters with law enforcement agencies $(P=0.001)$ (Table-II).

The mean age of severe opioid dependence (present) was $30.86 \pm 9.8$ and mean score of severity of dependence scale (SDS) was 10.53 \pm 2.3 whereas mean age of severe opioid dependence (absent) was $35.89 \pm 11.4$ and mean score of severity of dependence scale (SDS) were $9.19 \pm 3.09$. The $p$-value of severe opioid dependence based on age and severity of dependence scale (SDS) score is significant $(P=<0.007)$ which indicated that age significantly influenced the severity of opioid dependence and scores of severity of dependence scale (SDS) increase/decrease also significantly depend upon the age of user (Table-III).

\section{DISCUSSION}

In current study the relationship of severe opioid dependence with psychosocial factors was identified. 


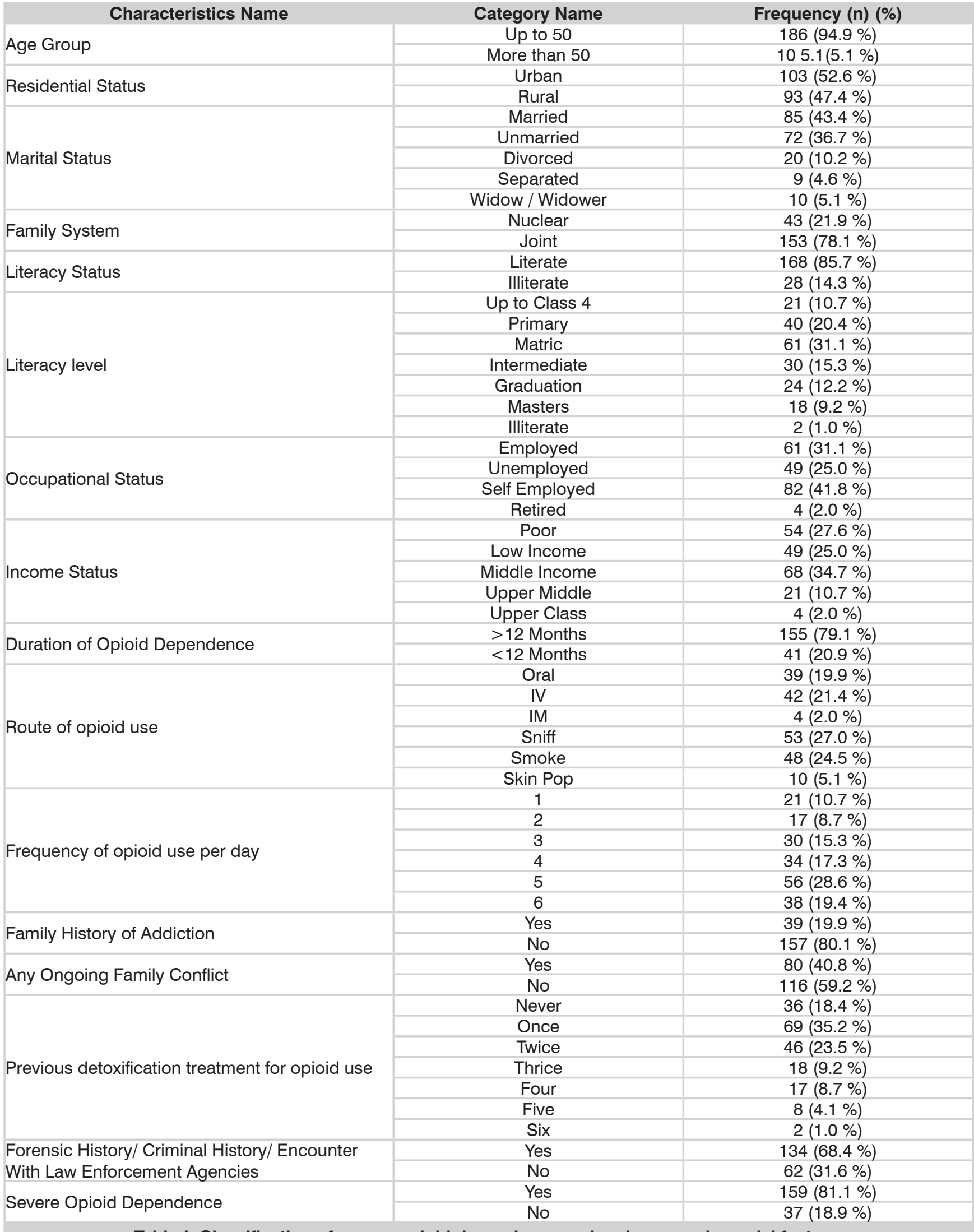

Table-I. Classification of severe opioid dependence and various psychosocial factors. 


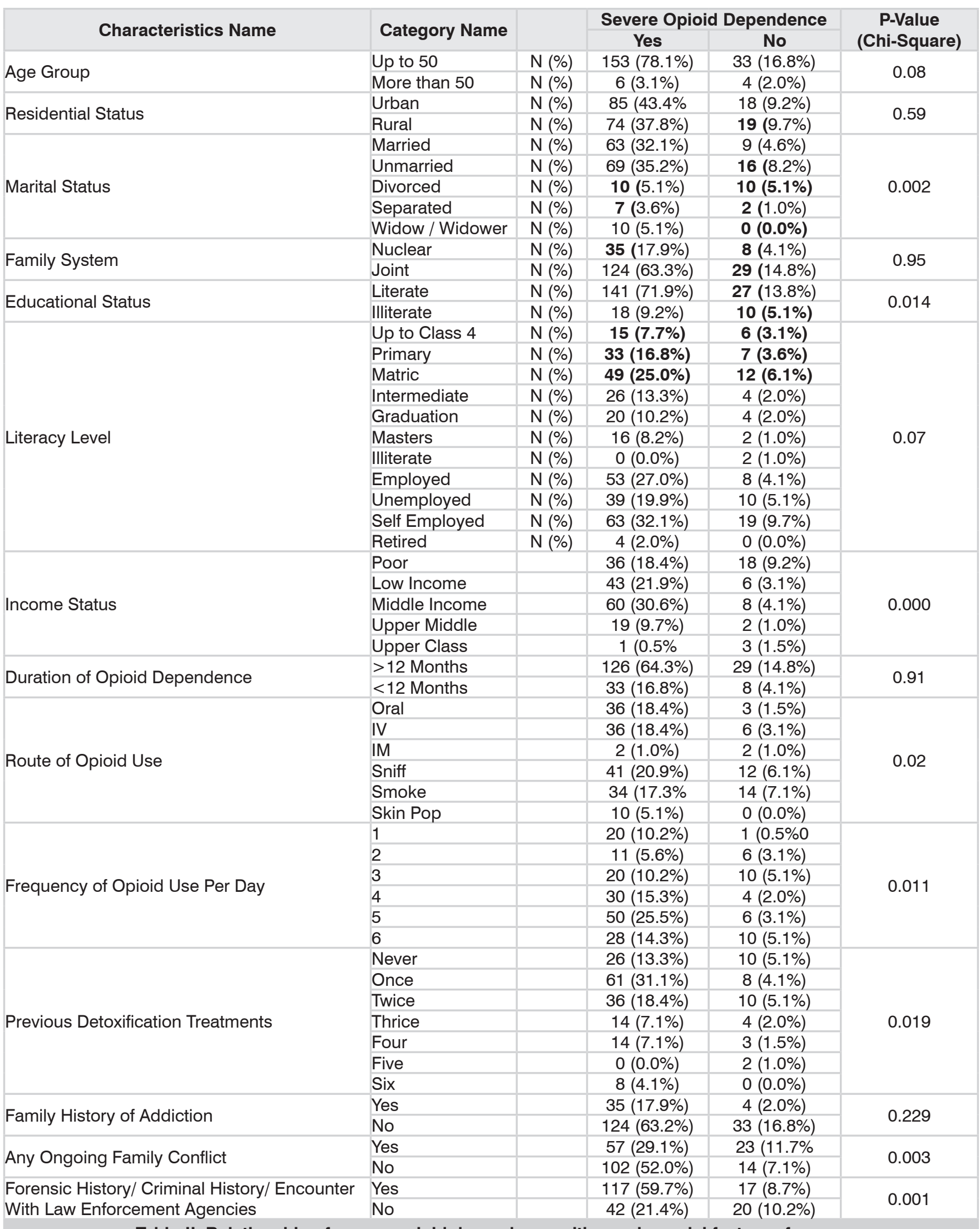

Table-Il. Relationship of severe opioid dependence with psychosocial factors of users. 


\begin{tabular}{|l|c|c|c|c|c|}
\hline & Severe Opioid Dependence & N & Mean & Std. Deviation & P-Value (T-test) \\
\hline \multirow{2}{*}{ Age } & Yes & 159 & 30.86 & 9.819 & 0.007 \\
\hline \multirow{2}{*}{ SDS Score } & No & 37 & 35.89 & 11.401 & 2.346 \\
\cline { 2 - 5 } & Yes & 159 & 10.53 & 3.099 & 0.017 \\
\hline
\end{tabular}

Table-III. Comparison of severe opioid dependence with age and Severity of Dependence Scale (SDS) Scores.

This study found supporting evidence for a critical relation of severe opioid dependence with certain psychosocial factors like age, literacy status, literacy level, marital status, employment status, monthly income, route of opioid use, duration of opioid use, frequency of daily opioid use, previous detoxification treatment for opioid use and encounters with law enforcement agencies.

The present study shows that majority of participants who had severe opioid dependence were of middle age. This finding is comparable with a study by Ahmad et al who found that most of the opioid users were young. Similar age pattern has been reported in other regions as well suggesting that adolescents and adults are at high risk for opioid use disorder. ${ }^{13}$ However our result regarding severe opioid dependence at middle age is supported by another study by Jabeen et al which stated that individuals starting drug use in young age are at increased risk of drug dependence later in life. ${ }^{14}$

Another study found that certain psychosocial factors like peer pressure, illiteracy/low education, employment status/occupation and related stresses influence substance abuse..$^{15}$ This is comparable to our study which documents severe opioid dependence was high and related with the middle income class and matric passed literate users. This finding suggests a significant role of income and education in precipitating severe opioid dependence. Nonetheless, these findings are in line with another study conducted in America which indicated similar income gradients and higher opioid dependence below $\$ 20,000$ annual household income which is consistent with American national data linking lower levels of income to opioid misuse. ${ }^{16}$ Our finding is also supported by an ecological study conducted in Southern California county from
2010 to 2014 which found higher education and income as protective factors against opioid related disorders. ${ }^{17}$

Our result shows that history of illicit substance use in family was not related with severity of opioid dependence. This finding contrasts with a previous study which showed that adolescents who indulge in opioid use have a strong family history of drug addiciton. ${ }^{18}$ Nonetheless his result suggests that genetic vulnerability or shared family environment or both may act differently regarding predisposition to opioid use disorder and opioid dependence. ${ }^{19}$ Another finding in the present study is that the majority of participants who were using opioids for more than a year had severe opioid dependence. This finding is in line with previous finding which concluded that extended period of opioid use places user at risk of dependency and addiction. ${ }^{20}$ Moreover this study found that severe opioid depenedent participants have had undergone previous detoxification treatment for opioid use however they relapsed. This finding is consistent with a study which reported high relapse rate of 32 to $70 \%$ even after opioid detoxification. ${ }^{21}$ The present study identified that participants with severe opioid dependence had significant encounters with law enforcement agencies which is comparable with a sociological research which highlights that neighborhoods with high crime and deviance rates are associated with higher rates of opioid misuse in socially disorganized areas. ${ }^{22}$

\section{CONCLUSION}

Mental healthfacilities in Pakistan generally provide pharmacological interventions as a sole treatment option for opioid addiction. opioid-addicted users exhibit severe dependence, which is related to different psychosocial factors, therefore along with pharmacological interventions, the clinicians 
and mental health professionals should also provide appropriately targeted and well designed psychosocial interventions to best suit patients' needs.

Copyright@ 12 Aug, 2021.

\section{REFERENCES}

1. American Psychiatric Association. Manual diagnostic and statistical of mental disorders $5^{\text {th }}$ ed. American Psychiatric Publishing. 2013, Arlington: pp. 540-546.

2. Chang HY, Kharrazi H, Bodycombe D, Weiner JP, Alexander GC. Healthcare costs and utilization associated with high risk prescription opioid use: A retrospective cohort study. BMC Med. 2018 May ;16(1):69.1

3. Vallersnes OM, Jacobsen D, Ekeberg $\varnothing$, Brekke M. Mortality, morbidity and follow-up after acute poisoning by substances of abuse: A prospective observational cohort study. Scand J Public Health. 2019 Jun; 47(4):452-461.

4. Dydyk AM. Jain NK. Gupta M. Opioid use disorder. 2020 Nov 20. In: StatPearls [Internet]. Treasure Island (FL): Stat Pearls Publishing, 2021 Jan-. PMID: 31985959.

5. UNODC and Ministry of Interior and Narcotics Control, Narcotics Control Division, Government of Pakistan. Drug Use in Pakistan 2013. Islamabad, Pakistan: UNODC; 2013.

6. Aslam N. Horrendous situation of substance abuse in Pakistan: A BirdÃc Â Â s Eye View on Socio-Demographics. Journal of Alcoholism \& Drug Dependence. 2015 Apr 2.

7. United Nations Office on Drugs and Crime (2018). Drug use in Nigeria.

8. United Nations Office on Drugs and Crime and World Health Organization: International Standards for the Treatment of Drug Use Disorders (2017).

9. The surgeon's general report on alcohol, drugs and health. Facing addiction in America. Report. US department of health and human services, America, 2016.

10. Sadock B J, Sadock V A, Ruiz P. Substance use and addictive disorders. $11^{\text {th }}$ ed. Philadelphia. Wolter kluwer. 2015, p.661-662.
11. Calculator s. Sample size calculator [Internet]. Calculator.net. 2021 [cited 4 June 2019].

12. Conway $k$ et al. Measuring addiction propensity and severity: The need for a new instrument. Drug Alcohol Depend. 2010 September 1; 111(1-2): 4-12.

13. Ahmad A, Khalique N, Khan Z, Amir A. Prevalence of psychosocial problems among school going male adolescents. Indian J Community Med. 2007; 32:21921.

14. Chloe J Jordan, Susan L Andersen. Sensitive periods of substance abuse: Early risk for the transition to dependence. Dev Cogn Neurosci. 2017 June; 25:2944.

15. Jabeen S, Raja M S, Saeed S et al. Factors influencing vulnerability towards heroin addiction in a Pakistani cohort. Pakistan J. Zool. 2016 November; 49(1):97-102.

16. George F Koob, Jay Schulkin. Addiction and stress: An allostatic view. Neurosci Biobehav Rev. 2019 Nov; 106:245-262.

17. CM Jones. Trends and key correlates of prescription opioid injection misuse in the United States. Addict Behav. 2018 March; 78:145-52.

18. Dick DM, Agrawal A. The genetics of alcohol and other drug dependence. Alcohol Res Health. 2008; $31(2): 111-8$.

19. Sarangi L, Acharya HP, Panigrahi OP et al. Substance abuse among adolescents in urban slums of sambalpur. Indian J Community Med. 2008 Oct; 33(4):265-7.

20. Warmkessel K. Researchers identify psychosocial factors that may help predict prolonged use of opioids after orthopaedic surgery (2017).

21. Chalana H, Kundal T, Gupta V, Malhari AS. Predictors of Relapse after Inpatient Opioid Detoxification during 1-Year Follow-Up. J Addict. 2016; 2016:7620860. doi: 10.1155/2016/7620860. Epub 2016 Sep 18. PMID: 27722007 ; PMCID: PMC5046044.

22. Ford JA, Sacra S, Yohros A. Neighborhood characteristics and prescription drug misuse among adolescents: The importance of social disorganization and social capital. Int J Drug Policy. 2017 Aug; 46:47-53. 


\section{AUTHORSHIP AND CONTRIBUTION DECLARATION}

\begin{tabular}{|c|l|l|l|}
\hline No. & Author(s) Full Name & \multicolumn{1}{|c|}{ Contribution to the paper } & Author(s) Signature \\
\hline 1 & Owais Kareem & $\begin{array}{l}\text { Literature search, study concept, } \\
\text { study design, data collection, data } \\
\text { interpretation, Drafting, revision for } \\
\text { accountability. } \\
\text { Study design, questionnaire } \\
\text { design, data analysis. }\end{array}$ \\
\hline 5 & Sohaib Hassan & $\begin{array}{l}\text { Study design, literature search, } \\
\text { questionnaire design. } \\
\text { Literature search, data collection, } \\
\text { drafting. } \\
\text { Literature search, data collection, } \\
\text { drafting. } \\
\text { Literature search, data collection, } \\
\text { drafting. }\end{array}$ \\
\hline
\end{tabular}

